\title{
Identifying drivers for bedtime social media use despite sleep costs: The adolescent perspective ${ }^{2}$ ?
}

\author{
Holly Scott, MSc*, Stephany M. Biello, PhD, Heather Cleland Woods, PhD \\ University of Glasgow, Glasgow, UK
}

\section{A R T I C L E I N F O}

\section{Article history:}

Received 28 March 2019

Received in revised form 4 July 2019

Accepted 11 July 2019

\section{Keywords:}

Social media use

Sleep

Adolescents

Fear of missing out

Focus groups

Thematic analysis

\begin{abstract}
A B S T R A C T
Objectives: Bedtime social media use is associated with poor sleep during adolescence, which in turn contributes to poor mental health, impaired daytime functioning and lower academic achievement. However, the underlying drivers for these bedtime social media habits remain understudied. This study adds an adolescent perspective on motivations for bedtime social media use and perceived impact on sleep.

Methods: Adolescents aged 11-17 years $(\mathrm{n}=24)$ participated in focus group discussions exploring their experiences of using social media, particularly at night. Inductive reflexive thematic analysis produced themes that captured underlying drivers for social media use and associated impact on sleep.

Results: Our analyses produced two overarching themes: Missing Out and Norms E Expectations. Adolescents' nighttime social media use was driven by concerns over negative consequences for real-world relationships if they disconnected (often reporting delayed bedtimes, insufficient sleep and daytime tiredness). These concerns included the risk of offline peer exclusion from missing out on online interactions, and the fear of social disapproval from violating norms around online availability and prompt responses. Conclusions: These findings offer novel insight into why adolescents may choose to prioritize social media over sleep. Researchers and practitioners can respond to the evolving needs of today's adolescents by approaching social media use not as a technology-based activity, but as an embedded social experience underpinned by the same concerns as offline interactions.
\end{abstract}

(C) 2019 The Authors. Published by Elsevier Inc. on behalf of National Sleep Foundation. This is an open access article under the CC BY license (http://creativecommons.org/licenses/by/4.0/).

\section{Introduction}

Adolescents tend to be highly driven social media users: nine out of ten 13- to 17-year olds now use social media, ${ }^{1}$ and young people often report a strong attachment to their online communication. ${ }^{2}$ By enabling 24/7 interactions, social media platforms can facilitate competition between social interactions and sufficient, good quality sleep, ${ }^{3-5}$ with incoming alerts and perceived social expectations of 24/7 availability presenting unique challenges for sleep compared to other forms of technology. ${ }^{6}$ Indeed, children as young as 11 report losing sleep due to social media sites ${ }^{7}$ and adolescents consistently identify social media use as the primary barrier to their sleep health. ${ }^{8,9}$ Understanding and tackling the sleep impact of social media is highly relevant for the adolescent population, since this developmental stage is characterized by a 'Perfect Storm' of biological

\footnotetext{
5u Funding source: Holly Scott is supported by an ESRC +3 PhD studentship.

* Corresponding author at: School of Psychology, University of Glasgow, 62 Hillhead Street, Glasgow, G12 8QB, UK.

E-mail address: h.scott.1@research.gla.ac.uk. (H. Scott).
}

and psychosocial changes that promote later bedtimes, which mean that short and ill-timed sleep are the norm when combined with early rise times for school. ${ }^{10,11}$ This is an important area of concern for parents, educators, practitioners and policymakers, since insufficient and poor quality sleep have negative consequences across a range of dimensions, including mental health, academic achievement and interpersonal functioning. ${ }^{12-15}$ Sleep interventions for today's adolescents must therefore address social media habits as part of supporting sufficient, good quality sleep, which may also bring about associated improvements in school experiences and mental health. ${ }^{16,17}$ In order to effectively support healthy social media habits for sleep, we first need to understand the cognitive, emotional and social drivers that underpin adolescents' bedtime social media engagement.

Available evidence now clearly supports associations between adolescent sleep patterns and social media use, with young people who spend more time using social media (especially at bedtime) and those who feel more emotionally connected to platforms reporting later bedtimes, longer sleep onset latency, shorter sleep duration and poorer sleep quality. ${ }^{5,18-22}$ Several likely mechanisms have 
been proposed to explain this link between adolescent sleep and bedtime social media use, alongside other technologies. ${ }^{23,24}$ Firstly, social media (and other technology use) may directly displace sleep by delaying bedtimes, resulting in shorter sleep duration. ${ }^{5,19,23,25}$ This is particularly relevant during adolescence, since school timetables typically prevent adolescents from using later rise times to compensate for delayed bedtimes. ${ }^{12,26}$ Secondly, bedtime social media use may also increase cognitive arousal before sleep, lengthening the time taken to fall asleep and impacting on sleep duration and quality. ${ }^{20,27}$ In addition, exposure to screen light (which is particularly rich in blue light) can have an alerting effect and delay the circadian rhythm, ${ }^{28,29}$ although it is important to note the small effect sizes reported and to consider screen light alongside the content and quality of screen-based activities and online interactions. ${ }^{30}$ Furthermore, associations between social media use and sleep are complex, likely involving interactive and bidirectional effects, for example including the use of social media as a sleep aid or coping strategy amongst poor sleepers. ${ }^{31,32}$ Although some recent examples of longitudinal and experimental work have supported causal links (in both directions) between general technology use and adolescent short sleep, ${ }^{33,34}$ the field remains limited by its reliance on cross-sectional data that precludes conclusions of causality and tends to examine only the frequency and duration of social media use, often grouped together with other technologies. ${ }^{21}$ This has limited our understanding of the unique mechanisms linking adolescent sleep and social media use specifically, whose inherently social and interactive nature presents unique implications for sleep processes. ${ }^{35}$ There is an opportunity to extend current understanding by bringing an alternative approach to this research area: employing qualitative methods to explore underlying motivations, thus adding the missing adolescent voice to this literature. This can build on existing evidence that bedtime social media use is linked to adolescent sleep patterns, ${ }^{5,18-20}$ to offer novel in-depth insight into what actually drives these bedtime social media use habits.

Research on adolescent social media use has reached an important juncture in its evolution: despite widespread media and public attention to its possible negative impacts on sleep and other areas of wellbeing, there is also important work highlighting potential benefits, such as increased social connectedness and belonging. ${ }^{36,37}$ This presents a challenge for educators, practitioners and policymakers, with available literature highlighting both positive and negative associated outcomes, based largely on evidence that is limited by its focus only on frequency and duration of use. ${ }^{18}$ In response to this, the current study takes a novel approach to studying adolescent sleep and social media use, by using in-depth analysis of focus group data to provide a deeper insider understanding of what actually drives adolescents' social media engagement at bedtime. It explores how these underlying drivers influence bedtime social media habits and experiences that negatively impact on sleep. This responds to the need to first understand what is driving bedtime social media use, before we can successfully support healthier social media habits that maintain sufficient, good quality sleep during adolescence. Our approach aims to give adolescents a voice in the literature on sleep and social media use, which has so far been underrepresented, but which has the potential to inform research, policy and practice in this area.

\section{Methods}

\section{Participants}

Participants were 24 adolescents (12 male, 12 female) aged $11-17$ years ( mean $=14.3$ years) attending a large state $S c o t t i s h ~ s e c-$ ondary school (broadly equivalent to US grades 6 to 11). The study was advertised to classes by a teacher, and was open to all pupils (regardless of their social media or sleep habits). The only inclusion criterion was sufficient English language ability to participate in a focus group. Participants were not reimbursed for taking part in the study.

\section{Data collection}

Participants took part in one of four focus groups, each with six participants, in a quiet room at their school. Focus groups were stratified by gender and age (11-14 and 15-17 years). The purpose of this stratification was not to identify different themes by gender or age, but to encourage participants to speak freely in a group of similar individuals. ${ }^{38}$ Participants were also informed that no identifying information would be shared, to encourage free speaking. HS moderated the focus groups using open ended questions and prompts where necessary to facilitate a group discussion around social media habits (particularly around bedtime), motivations for social media engagement and any perceived impact on sleep. Table 1 provides the initial questions and example prompts used to guide focus group discussions. Follow up questions were used to further explore relevant participant comments, allowing for unexpected insights around the topic. A second researcher made detailed notes to aid speaker identification during transcription and to capture nonverbal agreements between participants. Focus groups lasted between 45 minutes and 1 hour.

Ethical approval was granted by the University of Glasgow Science and Engineering Ethics Committee and the relevant Local Education Authority. Consent was given by all participants, including signed parental consent for those under 16. Participants were encouraged to seek support from their assigned pastoral care teacher (responsible for student wellbeing) if they had any concerns about their sleep or social media use.

\section{Data analysis}

Focus group discussions were digitally audio recorded and transcribed orthographically by HS, assigning each participant a pseudonym. The transcript data were entered into NVivo $11^{39}$ to facilitate analysis. Data were analyzed using Braun and Clarke's method for reflexive thematic analysis, ${ }^{40,41}$ which aims "to provide a coherent and compelling interpretation of the data, grounded in the data." $42 \mathrm{We}$ carried out our analysis within an experiential, contextualist

Table 1

Focus group question guide

\begin{tabular}{|c|c|}
\hline Initial topic question & $\begin{array}{l}\text { Potential follow up questions/prompts if } \\
\text { required }\end{array}$ \\
\hline Do you use social media? & $\begin{array}{l}\text { What sites/apps? } \\
\text { How often? When? } \\
\text { What for? }\end{array}$ \\
\hline \multicolumn{2}{|l|}{ Why do you use social media? } \\
\hline $\begin{array}{l}\text { How do you feel when you are not } \\
\text { using social media? }\end{array}$ & $\begin{array}{l}\text { Pleasant or unpleasant? } \\
\text { Why is that? }\end{array}$ \\
\hline \multicolumn{2}{|l|}{$\begin{array}{c}\text { Could you tell us about your social } \\
\text { media habits around bedtime? }\end{array}$} \\
\hline $\begin{array}{l}\text { Do you think that social media } \\
\text { affects your sleep? }\end{array}$ & $\begin{array}{l}\text { If so, how? If not, what makes you say } \\
\text { that? }\end{array}$ \\
\hline & $\begin{array}{l}\text { Does it affect what time you go to bed at } \\
\text { / how long it takes you to fall asleep? } \\
\text { Do alerts keep you awake or wake you } \\
\text { up at night? }\end{array}$ \\
\hline $\begin{array}{l}\text { Do you ever use social media when } \\
\text { you can't sleep or to help you } \\
\text { sleep? }\end{array}$ & $\begin{array}{l}\text { Do you ever use it to pass time until you } \\
\text { fall asleep? } \\
\text { If so / if not, why is that? }\end{array}$ \\
\hline
\end{tabular}

Notes: the facilitator referred to this guide of questions and follow up prompts to start and maintain a group discussion that covered the intended topics. These questions were used flexibly to facilitate discussion, not as a strict list of verbatim questions. 
framework to focus on participants' experiences and interpretations as expressed through their own language ${ }^{43}$ : for example what they felt constituted 'normal' teenage behavior. This analysis took an inductive approach to coding and developing themes that were closely linked to the data, remaining open to unexpected insights, given the scarcity of existing qualitative research on this topic. The analysis involved complete coding, working systematically through each focus group transcript, identifying and labelling all data chunks that were relevant to the research question. ${ }^{40}$ Codes were then grouped into candidate themes that reflected "pattern[s] of shared meaning, organized around a core concept or idea". ${ }^{42}$ These were reviewed, revised and refined to ensure that the final theme names and definitions coherently and faithfully represented the coded data excerpts and the dataset as a whole. ${ }^{41} \mathrm{HS}$ carried out the coding and initial theme generation, engaging in regular discussion and critical reflection with SMB and HCW throughout all analytical stages. ${ }^{42}$ The authors also discussed the analysis in-depth with colleagues with expertise in qualitative research methods. These steps ensured a rigorous analytical approach that produced final themes that provide a faithful and meaningful interpretation of the data in relation to the research question. ${ }^{42}$ Presented illustrative quotes have been edited to facilitate reading ease, indicated by [...].

\section{Results}

Participants reported using popular social media platforms (e.g. Snapchat, Instagram, Facebook, Twitter, WhatsApp) in line with prevalence statistics for this age group, ${ }^{44}$ but their natural language then tended to focus more on the social interactions facilitated by these platforms rather than specific platforms themselves. Our analyses produced two overarching themes that captured underlying drivers for social media engagement, with a specific focus on how these were expressed in bedtime social media behaviors with consequences for sleep habits. Missing Out reflects the constant perceived threat of missing out on social media content and interactions when offline, which motivated participants to initiate and maintain bedtime social media engagement to avoid negative consequences for real-world relationships. Norms and Expectations captures the shared sense of how a perceived 'normal' teenager should use social media (e.g. being active, engaged and available online) which led some participants to continue interactions late at night to avoid social disapproval from violating etiquette. Therefore, whilst both themes capture difficulties disengaging from bedtime social media use due to considerations around social connection and inclusion, they each retain a unique focus: Missing Out looks inwards to capture the individual's own desire to stay connected, whereas Norms and Expectations looks outwards to capture perceived expectations from others. Table 2 summarizes the structure and scope of these two overarching themes and their sub-themes. Tables 3 and 4 provide illustrative verbatim quotes for each sub-theme of Missing Out and Norms and Expectations, respectively.

\section{Missing out}

\section{Offline costs}

There was a shared concern with the offline consequences of not being active on social media, especially during peak time around bedtime when participants reported that peers were most active. This reflected the lack of perceived boundary between online and offline social worlds, with online interactions and content providing shared references and group jokes in later face-to-face settings. Not being active on social media at bedtime meant that one risked missing online conversations, resulting in feeling left out of face-to-face peer interactions the following day, accompanied by feelings of frustration, loneliness and paranoia.
Table 2

Theme structure and definitions

\begin{tabular}{ll}
\hline $\begin{array}{l}\text { Overarching } \\
\text { theme }\end{array}$ & Sub-themes and definitions \\
\hline & $\begin{array}{l}\text { Offline costs } \\
\text { Online interactions support later face-to-face interactions } \\
\text { through shared references and group jokes. Not being active } \\
\text { on social media (especially at 'peak time' late at night) } \\
\text { creates a perceived risk of later offline exclusion. } \\
\text { Constant threat } \\
\text { Fear of real-world exclusion means that not being connected } \\
\text { to social media is experienced as a state of threat, with a } \\
\text { constant worry and bedtime rumination about potentially } \\
\text { being left out when offline. } \\
\text { Can't disengage } \\
\text { The desire to avoid missing out online (with 'real-world' } \\
\text { offline costs) initiated and maintained social media } \\
\text { engagement past intended bedtimes, making it difficult to } \\
\text { disengage and delaying sleep onset. }\end{array}$ \\
$\begin{array}{l}\text { Normal teenager } \\
\text { According to shared norms and expectations, a 'normal' } \\
\text { teenager should be an active, engaged social media user, } \\
\text { expectations } \\
\text { with online availability and prompt responses (including } \\
\text { late at night). } \\
\text { Violating etiquette } \\
\text { Violating unspoken expectations around online availability } \\
\text { and interactions (e.g. with slow responses) is judged to be } \\
\text { 'incorrect' behavior, creating anxiety and guilt for some and } \\
\text { a sense of rebellion for others. } \\
\text { Obligation } \\
\text { An awareness of these norms and expected behaviors can } \\
\text { maintain online social interactions past intended bedtimes, } \\
\text { despite tiredness, out of a sense of obligation rather than } \\
\text { enjoyment. }\end{array}$ \\
\hline
\end{tabular}

\section{Constant threat}

Being offline was therefore experienced as a state of constant threat, with some reporting intrusive thoughts and an inescapable worry about potentially missing out on interactions or information. This created a particular tension between social media use and sleep habits, since continuing online interactions delayed bedtimes for many, but disengaging from social media could also impact on sleep by fueling cognitive arousal and rumination around potentially missing out.

\section{Can't disengage}

The desire to neutralize this perceived threat initiated and maintained social media engagement beyond intended bedtimes, driving participants to check accounts and also making it difficult to disengage. Participants reported delayed sleep onset due to difficulties disengaging from social media at bedtime and resisting the temptation to re-engage with incoming notifications, despite attempts to self-regulate use.

\section{Norms and expectations}

\section{Normal teenager}

There was a shared agreement of how the perceived 'normal' teenager uses social media. These unspoken norms included being an active, engaged social media user who is available online and has a sense of immediacy in checking new content and responding to messages, including around bedtime. This formed an expected etiquette around social media interactions, with a sense of being different from the perceived typical adolescent if one went against these norms of responding immediately and being constantly available.

\section{Violating etiquette}

Disengaging from social media at bedtime and failing to respond to messages promptly was therefore acknowledged as 'incorrect' 
Table 3

'Missing out': sub-themes and illustrative quotes

\begin{tabular}{|c|c|}
\hline Sub-theme & Illustrative quotes \\
\hline $\begin{array}{r}\text { Offline } \\
\text { costs }\end{array}$ & $\begin{array}{l}\text { "If like the night before something big happened and then the } \\
\text { next day everyone is talking about it and if you've not seen it } \\
\text { you're kind of just like 'oh, I've not seen that or I've not been } \\
\text { involved'. So it affects the next day as well." (Olivia, 14) }\end{array}$ \\
\hline & $\begin{array}{l}\text { "If you've not seen something that everybody else has seen [...] } \\
\text { then they have a joke between them, it's sort of annoying } \\
\text { because you don't know what they're talking about. You think } \\
\text { 'maybe they're talking about me, maybe they're talking about } \\
\text { somebody else'. You sort of feel a bit paranoid." (Harry, 16) } \\
\text { "Yeah then it sort of leads to exclusion and you feel paranoid that } \\
\text { you're not included in that." (Daniel, 15) }\end{array}$ \\
\hline $\begin{array}{c}\text { Constant } \\
\text { threat }\end{array}$ & $\begin{array}{l}\text { "It's like the worst thing ever [...] You try to like do other things } \\
\text { just to occupy you but it's always at the back of your mind that } \\
\text { you don't have your phone in your hand or in your bag } \\
\text { somewhere." (Jessica, 16) "Yeah and you always think } \\
\text { something's going on and you're missing out on everything." } \\
\text { (Megan, 15) }\end{array}$ \\
\hline
\end{tabular}

"As soon as you give into that temptation you're on it for an hour, two hours at least and then- so yeah, I would say it always affects your sleep. And then you're always wondering 'what's everyone else doing? Are they speaking to each other? Am I missing out? Should I be on this? Should I be up?' And then yeah- it affects my sleep." (Daniel, 15)

"if you're not on [social media], something could happen" (Olivia, 14)

"it's always in the back of your head and it's sort of like if you've forgotten to do something and it keeps picking at you and you just feel like you need it or you need to do it" (Sophie, 15)

"there might be something going on and you want to hear about it" (Matthew, 13)

Can't "When you're trying to go to sleep and you say 'right I'm going to

disengage put my phone down' and then you hear a buzz so you keep checking it [...] You just feel like sometimes you can miss something big [...] and then they ask, your friends ask 'oh yeah, you missed out' or like 'what happened? What happened?' and you're like 'well, I went to sleep'. I think that you feel the need to so that you feel like you are part of something." (Katie, 13)

"Once everything is checked you are like 'okay finally now I can sleep' so it's good when it's done" (Lauren, 14)

"You feel like you have to answer at night even though you're trying to sleep. It might be important or you might miss out on something" (Benjamin, 16)

“Like when you're done talking to someone or you're done checking Snapchat or something, the stories, you're done with that. Then you go on to Instagram, you have to look at everything there. Then you have to go back on Snapchat because someone has messaged you or there's more stuff. So this keeps on happening and then there is like Facebook or something you have to check. It's stuff like that, it just keeps going until like 12." (Lauren, 14)

behavior, by violating etiquette and norms around expected online availability. For some participants, this was experienced as a sense of independence and rebellion against norms, despite possible social disapproval. For others, this was associated with feelings of guilt, anxiety or self-doubt, including questioning whether one should reengage on social media at bedtime.

\section{Obligation}

An acute awareness of these social rules governing online interactions meant that some participants felt disempowered to disengage
Table 4

'Norms \& expectations': sub-themes and illustrative quotes

\begin{tabular}{ll}
\hline Sub-theme & Illustrative quotes \\
\hline $\begin{array}{c}\text { Normal } \\
\text { teenager }\end{array}$ & $\begin{array}{l}\text { "It's rare that you get a teenager that wouldn't be so into the } \\
\text { internet and social media and stuff like that." } \\
\end{array}$ \\
& "I think everyone probably has a basic Facebook." \\
& "Yeah, it's like unheard of." (Emily \& Jessica, both 16)
\end{tabular}

"If you're left out and stuff and you don't have social media it would be kind of awkward ... if you're one of those few people that don't have it then it's a bit difficult" (Katie, 13)

"We're so engaged in social media now and we're so used to it. We're just like 'yeah, this conversation can't wait' ... it's kind of consuming." (Emily, 16)

"You're so used to using it [in bed] and all the people you're in contact will be as well. So you take it for granted. You don't think about sleep or what time it is." (Luke, 12)

\begin{tabular}{cl}
\hline $\begin{array}{c}\text { Violating } \\
\text { etiquette }\end{array}$ & $\begin{array}{l}\text { "I'm so bad at like messaging and stuff like that. I'll just leave } \\
\text { why I like their pictures to let them know that I'm still here, } \\
\text { I'm alive." (Jessica, 16) }\end{array}$
\end{tabular}

"After a certain point I just stop reading my notifications. I just do my own thing, like watch something and I just don't care about what anyone says." (Ellie, 16)

"I'm guilty of this but sometimes if it's not someone special, like that I don't want to talk to, I just kind of ignore it for a bit $[\ldots]$ but if it's someone like I do want to talk to then I'm like 'OK yeah' so I open it straightaway." (Lauren, 14)

"You're always wondering 'What's everyone else doing? [...] Should I be on this? Should I be up?' And then yeah- it affects my sleep." (Daniel, 15)

Obligation "If you send someone a picture and then they send you one back and it just goes on for ages and you just send random pictures to each other and then it keeps going on I feel like that might keep you up or-"

"Yeah because if the conversation is going good you need to keep it going, you can't ignore them or else that's just rude" "You feel rude"

"Very rude" (Olivia \& Lauren, both 14)

"You also don't want to offend the other person by leaving [...] You'll think 'have I upset them? Is there a way where I can justify leaving? Can I say “look, I'm tired"?' [...] Somebody else will message you being 'everybody's gone to sleep, wanna stay up and chat?' and you don't really want to say 'no' and you can't just leave them because you've already read it and they've seen that you read it. So you sort of get stuck talking to a person." (Harry, 16)

from social media in order to sleep, as ending an ongoing interaction was simply not an option due to the etiquette constructed around social media use. There was a shared concern about causing offense to peers by failing to respond to messages, leading some to maintain online interactions, despite tiredness, out of a sense of obligation rather than enjoyment.

\section{Discussion}

This study adds to current understanding of adolescents' social media and sleep habits, by using qualitative methods to uncover powerful drivers and concerns underlying bedtime social media use and difficulties disengaging. The current analyses produced two overarching themes - Missing Out and Norms and Expectations - that offer fresh insight, from an adolescent perspective, into why young people may choose to prioritize social media use over even the basic physiological need for sleep. ${ }^{45}$ Firstly, concern over missing online 
interactions and experiencing exclusion in later face-to-face peer settings can contribute to difficulties disengaging from social media, with delayed sleep onset and increased arousal at bedtime. Secondly, perceived social expectations around online availability and etiquette can cause some adolescents to continue online interactions despite tiredness or a desire to sleep, for fear of causing offense to peers. Together these themes highlight powerful socially-driven motivations for maintaining bedtime social media interactions despite potential sleep costs, leading some adolescents to continue interactions at night either to satisfy their own desire to feel connected and involved (Missing Out) or to maintain esteem by meeting perceived expectations from others (Norms and Expectations).

Overall, these findings suggest that adolescents' difficulty disengaging from social media at night is underpinned by concerns over negative consequences for peer relationships. Continued social media activity - often beyond intended bedtimes and despite tiredness - seems to be largely driven by the same well-established underlying factors that influence face-to-face interactions, such as a desire to feel included and pressure to follow group norms. ${ }^{46,47}$ These social drivers are likely to become especially salient during adolescence, when self-esteem is particularly contingent on social acceptance and approval. ${ }^{48}$ Whilst these social processes are not a new phenomenon, now the possibility of $24 / 7$ connection via social media platforms allows social activity to easily compete with sleep, as individuals can maintain these interactions in bed, increasing arousal and delaying sleep onset. ${ }^{19}$ Therefore, whilst there is nothing new about the current teenage generation's desire for social connection and peer acceptance, ${ }^{49,50}$ a rapidly evolving media landscape $h a s$ altered how these processes directly compete with sleep opportunity. Smartphone ownership is now an almost ubiquitous feature of adolescence, ${ }^{44}$ and this increased access to personal hand-held devices means that it is especially challenging for today's parents to limit online interactions at bedtime. ${ }^{8}$

These findings extend current understanding of the unique processes affecting sleep during adolescence specifically. They add deeper insight into the role of social media use, which is one of the sleep-delaying psychosocial factors identified in the 'Perfect Storm' model of adolescent sleep. ${ }^{10,11}$ Together with biological changes to sleep regulation processes, bedtime social media use and other psychosocial factors tend to promote later sleep onset during adolescence, which results in short and ill-timed sleep when combined with typical early school day rise times. ${ }^{10}$ The Perfect Storm model notes that adolescence is a period characterized by increasing independence, which includes autonomy over sleep timing and bedtime habits. In addition to increased independence, the current findings highlight the need to also consider how adolescent sleep is shaped by this period's characteristic heightened sensitivity to social influences. ${ }^{49}$ Since adolescents are primed to avoid social risk and tend to weigh this more heavily than other risks (e.g. health costs), ${ }^{50}$ it is understandable why some may choose to prioritize staying connected and following perceived etiquette over getting sufficient sleep. This new insight therefore supports an approach to researching and treating adolescent sleep within a holistic model of adolescent development and functioning more widely, since social processes clearly play an important role in the sleep behaviors and experiences of young people navigating this period of intense development in today's 24/7 connected world.

Furthermore, our findings indicate that this overarching concern over possible relationship costs of disconnecting at night seems to focus primarily on the impact on 'real-world' offline peer interactions. This builds on existing evidence that adolescents tend not to distinguish between online and offline worlds, ${ }^{45}$ instead seeing social media interactions as an extension of their face-to-face relationships. ${ }^{51}$ This highlights the value of bringing the adolescent voice to the sleep research literature, since this focus on the social interactions - rather than the devices or platforms themselves - contrasts with the prevalent "screentime" focused research often with measures that focus on the device or specific platform. ${ }^{21}$ Furthermore, whilst adults also report feeling anxious, unpleasant and disconnected without access to their devices, ${ }^{2,52}$ this negative experience may be particularly intense for adolescents who tend to consider social media interactions as more 'real' than older generations. ${ }^{45}$ Efforts aiming to support adolescents in developing healthy social media habits for sleep must therefore approach bedtime social media engagement not as a form of technology use, but instead as an embedded social experience. Such approaches should consider the likely distress arising from disconnecting, with an associated increase in pre-sleep cognitive arousal, which could be tackled with cognitive behavioral- or mindfulness-based techniques. ${ }^{53,54}$

These novel insights can help reconcile existing evidence of both positive and negative health and wellbeing outcomes associated with social media use, as research has demonstrated that heavier users tend to report poorer sleep patterns, ${ }^{3,5,18,20}$ but also benefits such as increased social connectedness and sense of belonging. ${ }^{36,37}$ The current findings suggest that adolescents face a trade-off between these benefits and costs of using social media at night, and must balance the desire for inclusion and belonging in offline peer settings the following day with the need for sufficient sleep, avoiding delayed bedtimes and daytime tiredness. Whilst continuing nighttime online interactions provides an opportunity for immediate social connection, if the associated delayed sleep onset results in insufficient sleep (particularly likely on school nights) ${ }^{10}$ then this could have an indirect impact on daytime functioning, including interpersonal functioning. ${ }^{15,55}$ This highlights the importance of uniting research that has to date largely examined social media's links to sleep and to other aspects of wellbeing or interpersonal functioning in isolation, to now move forward and build a more holistic understanding of social media's role in adolescent functioning as a whole. $^{21}$

Interestingly, our analyses highlighted individual differences in how adolescents balanced social media and sleep. Some participants reported delayed bedtimes, insufficient sleep and daytime tiredness, resulting from ongoing social media activity at night - despite attempts to self-regulate, as has been previously documented ${ }^{56}$ - due to a sense of obligation or concern over possible exclusion. In contrast, others reported less difficulty in disengaging from social media to sleep, despite expressing an awareness of possible social disapproval. This is consistent with existing evidence of different profiles of adolescent internet user: from those who feel 'stuck online' and unable to disengage, to those who feel able to balance internet use with other activities and needs. ${ }^{57}$ Differences in adolescents' level of difficulty disengaging from social media at night may be driven by underlying individual factors: for example, those who are more concerned about ostracism have been shown to experience a stronger sense of obligation to respond to social media messages. ${ }^{58}$ This can extend current models of adolescent technology use and sleep, by adding to identified factors that influence sleep-relevant technology behaviors. For example, Cain and Gradisar's model ${ }^{23}$ (recently updated by Bartel and Gradisar $)^{24}$ notes parental involvement and flow as likely factors that influence technology habits that have implications for child and adolescent sleep. The current findings indicate that in the case of social media specifically, a crucial determining factor is the extent to which individuals experience concerns about staying connected and following etiquette.

Overall, the current findings suggest that - rather than time spent using social media sites - sleep research and practice should focus more on the extent to which individuals experience difficulties disengaging and the drivers that underpin this negative experience. This would shift the focus away from setting time limits on daily or nightly use, towards facilitating a healthier overall relationship with 
social media platforms, which optimizes wellbeing by maximizing benefits like connectedness ${ }^{36,37}$ whilst minimizing disruption to sufficient, good quality sleep. . $^{3,5,18,20}$

These findings should be interpreted within the limitations of the current study, including its relatively small sample of adolescents attending a single school in Scotland. The purpose of this type of qualitative analysis is not to achieve generalizability in a statistical sense, but instead to gain rich insight and in-depth understanding. ${ }^{40} \mathrm{How}-$ ever, given that the current results reflect existing evidence on both online communication ${ }^{2,45,52}$ and broader social processes, ${ }^{46,47}$ the issues highlighted by these findings are likely to be relevant for adolescents more broadly. These insights can contribute to available evidence and help to inform future work that explores these issues further.

\section{Conclusions}

This in-depth qualitative analysis highlights common cognitive, emotional and social drivers that can maintain bedtime social media engagement despite negative sleep consequences. These findings suggest that researchers and practitioners can respond to the evolving needs of today's adolescents by approaching social media use not as a technology-based activity, but as an extension of faceto-face interactions, underpinned by the same underlying social drivers and concerns. For example, future research can build on these findings to develop methods to quantify the extent to which individuals experience this difficulty disengaging from social media at night. Further work can also explore what individual differences explain this variation, whereby some adolescents can easily disengage from social media to sleep, whilst others experience a strong preoccupation with possible consequences of disengaging, reporting delayed bedtimes and increased arousal. In terms of practice, efforts to encourage healthy social media habits for sleep should consider the difficulty and possible distress associated with disconnecting at night, for example by incorporating cognitive behavioral- or mindfulness-informed approaches.

\section{Acknowledgements}

The authors would like to thank Prof Niamh Stack, Dr Kate Reid and the Qualitative Methods Group at the University of Glasgow for their helpful feedback on the study proposal and initial analyses, and Amy Blackley for assistance with data collection. This work was supported by an ESRC +3 PhD studentship for Holly Scott (grant number $\mathrm{ES} / \mathrm{J} 500136 / 1$ ).

\section{References}

1. Lenhart A. Teens, Social Media \&' Technology Overview 2015. Pew Research Centre; 2015.

2. Vorderer P, Kromer N, Schneider FM. Permanently online-permanently connected: explorations into university students' use of social media and mobile smart devices. Computers in Human Behavior. 2016;63:694-703.

3. Levenson JC, Shensa A, Sidani JE, Colditz JB, Primack BA. The association between social media use and sleep disturbance among young adults. Prev Med. 2016;85: $36-41$.

4. Levenson JC, Shensa A, Sidani JE, Colditz JB, Primack BA. Social media use before bed and sleep disturbance among young adults in the United States: a nationally representative study. Sleep. 2017;40(9):zsx113-zsx113.

5. Orzech KM, Grandner MA, Roane BM, Carskadon MA. Digital media use in the $2 \mathrm{~h}$ before bedtime is associated with sleep variables in university students. Computers in Human Behavior. 2016:55:43-50.

6. Thomee S, Dellve L, Harenstam A, Hagberg M. Perceived connections between information and communication technology use and mental symptoms among young adults-a qualitative study. BMC Public Health. 2010;10:66.

7. Espinoza G, Juvonen J. The pervasiveness, connectedness, and intrusiveness of social network site use among young adolescents. Cyberpsych Beh Soc N. 2011;14 (12):705-709.

8. Godsell S, White J. Adolescent perceptions of sleep and influences on sleep behaviour: a qualitative study. J Adolesc. 2019;73:18-25.
9. Quante M, Khandpur N, Kontos EZ, Bakker JP, Owens JA, Redline S. "Let's talk about sleep": a qualitative examination of levers for promoting healthy sleep among sleep-deprived vulnerable adolescents. Sleep Med. 2018.

10. Carskadon MA. Sleep in adolescents: the perfect storm. Pediatr Clin North Am. 2011;58(3):637-647

11. Crowley SJ, Wolfson AR, Tarokh L, Carskadon MA. An update on adolescent sleep: new evidence informing the perfect storm model. J Adolesc. 2018;67:55-65.

12. Owens J. Insufficient sleep in adolescents and young adults: an update on causes and consequences. Pediatrics. 2014;134(3):E921-E932.

13. Alfano CA, Zakem AH, Costa NM, Taylor LK, Weems CF. Sleep problems and their relation to cognitive factors, anxiety, and depressive symptoms in children and adolescents. Depress Anxiety. 2009;26(6):503-512.

14. Fredriksen K, Rhodes J, Reddy R, Way N. Sleepless in Chicago: tracking the effects of adolescent sleep loss during the middle school years. Child Dev. 2004;75(1): $84-95$

15. Kyle SD, Espie CA, Morgan K. "...Not just a minor thing, it is something major, which stops you from functioning daily": quality of life and daytime functioning in insomnia. Behav Sleep Med. 2010;8(3):123-140.

16. Vernon L, Barber BL, Modecki KL. Adolescent problematic social networking and school experiences: the mediating effects of sleep disruptions and sleep quality. CyberPsychology, Behavior \& Social Networking. 2015;18(7):386-392.

17. Vernon L, Modecki KL, Barber BL. Tracking effects of problematic social networking on adolescent psychopathology: the mediating role of sleep disruptions. Journal of Clinical Child E' Adolescent Psychology. 2017;46(2):269-283.

18. Woods HC, Scott H. \#Sleepyteens: social media use in adolescence is associated with poor sleep quality, anxiety, depression and low self-esteem. J Adolesc. 2016;51:41-49.

19. Scott H, Woods HC. Fear of missing out and sleep: cognitive behavioural factors in adolescents' nighttime social media use. J Adolesc. 2018;68:61-65.

20. Harbard E, Allen NB, Trinder J, Bei B. What's keeping teenagers up? Pre-bedtime behaviors and actigraphy-assessed sleep over school and vacation. J Adolescent Health. 2016;58(4):426-432.

21. Scott H, Woods HC. Understanding links between social media use, sleep and mental health: recent progress and current challenges. Current Sleep Medicine Reports. in press; $5(3)$.

22. Scott H, Biello SM, Woods HC. Social media use and adolescent sleep patterns: cross-sectional findings from the UK Millennium Cohort Study. BMJ Open. in press.

23. Cain N, Gradisar M. Electronic media use and sleep in school-aged children and adolescents: a review. Sleep Med. 2010;11(8):735-742.

24. Bartel K, Gradisar M. New directions in the link between technology use and sleep in young people. In: Nevšímalová S, Bruni O, editors. Sleep Disorders in Children. Cham: Springer International Publishing; 2017. p. 69-80.

25. LeBourgeois MK, Hale L, Chang AM, Akacem LD, Montgomery-Downs HE, Buxton OM. Digital media and sleep in childhood and adolescence. Pediatrics. 2017;140 (suppl 2):S92-s96.

26. Tavernier R, Willoughby T. Sleep problems: predictor or outcome of media use among emerging adults at university? J Sleep Res. 2014;23(4):389-396.

27. Nicassio PM, Mendlowitz DR, Fussell JJ, Petras L. The phenomenology of the presleep state - the development of the pre-sleep arousal scale. Behav Res Ther 1985;23(3):263-271.

28. Chang A-M, Aeschbach D, Duffy JF, Czeisler CA. Evening use of light-emitting eReaders negatively affects sleep, circadian timing, and next-morning alertness. Proc Natl Acad Sci. 2015;112(4):1232-1237.

29. Figueiro M, Overington D. Self-luminous devices and melatonin suppression in adolescents. Light Res Technol. 2016;48(8):966-975.

30. Woods HC, Scott H. Merging the biological and social processes of sleep and screens. Current Sleep Medicine Reports. in press;5(3).

31. Exelmans L, Van den Bulck J. The use of media as a sleep aid in adults. Behav Sleep Med. 2016;14(2):121-133.

32. Exelmans L, Scott H. Social Media Use and Sleep Quality among Adults: The Role of Gender, Age and Social Media Checking Habit. 17 Apr 2019. 10.31234/osf.io/ eqxdh.

33. Bartel K, Scheeren R, Gradisar M. Altering Adolescents' pre-bedtime phone use to achieve better sleep health. Health Commun. 2018:1-7.

34. Mazzer K, Bauducco S, Linton SJ, Boersma K. Longitudinal associations between time spent using technology and sleep duration among adolescents. J Adolesc. 2018;66:112-119.

35. Carr CT, Hayes RA. Social media: defining, developing, and divining. Atlantic Jour nal of Communication. 2015;23(1):46-65.

36. Davis K. Friendship 2.0: adolescents' experiences of belonging and self-disclosure online. J Adolesc. 2012;35(6):1527-1536.

37. Davis K. Young people's digital lives: the impact of interpersonal relationships and digital media use on adolescents' sense of identity. Computers in Human Behavior. 2013;29(6):2281-2293.

38. Lindlof TR, Taylor BC. Qualitative Communication Research Methods. CA, USA SAGE Publications; 2010

39. NVivo [computer program]. Version 11: QSR International Pty Ltd; 2015

40. Braun V, Clarke V. Successful Qualitative Research. London, UK: SAGE Publications; 2013.

41. Braun V, Clarke V. Using thematic analysis in psychology. Qual Res Psychol. 2006;3 (2):77-101.

42. Braun V, Clarke V, Hayfield N, Terry G. Thematic analysis. In: Liamputtong P, editor. Handbook of Research Methods in Health Social Sciences. Singapore: Springer Singapore; 2019. p. 843-860. 
43. Willig C. Introducing Qualitative Research in Psychology. Buckingham, UK: Open University Press; 2001.

44. Pew Research Center. Teens, social media \& technology 2018. May 2018.

45. Redden SM, Way AK. 'Adults don't understand': exploring how teens use dialectical frameworks to navigate webs of tensions in online life. Journal of Applied Communication Research. 2017;45(1):21-41.

46. Sheldon KM, Bettencourt BA. Psychological need-satisfaction and subjective wellbeing within social groups. British Journal of Social Psychology. 2002;41(1):25-38.

47. Hogg MA, Reid SA. Social identity, self-categorization, and the communication of group norms. Commun Theory. 2006;16(1):7-30.

48. Wouters S, Verschueren K, Briers V, Janssen R. Development and validation of a self-esteem contingency questionnaire for adolescents. Pers Indiv Differ. 2016;99: 295-301.

49. Blakemore S-J, Mills KL. Is adolescence a sensitive period for sociocultural processing? Annu Rev Psychol. 2014;65:187-207.

50. Blakemore S-J. Avoiding social risk in adolescence. Curr Dir Psychol Sci. 2018;27 (2):116-122.

51. Assunção RS, Matos PM. Perspectives of adolescents about Facebook use: a qualitative study. Psicologia em Estudo. 2014;19:539-547.

52. Cheever NA, Rosen LD, Carrier LM, Chavez A. Out of sight is not out of mind: the impact of restricting wireless mobile device use on anxiety levels among low, moderate and high users. Computers in Human Behavior. 2014;37:290-297.

53. Cincotta AL, Gehrman P, Gooneratne NS, Baime MJ. The effects of a mindfulness-based stress reduction programme on pre-sleep cognitive arousal and insomnia symptoms: a pilot study. Stress and Health. 2011;27 (3):e299-e305.

54. Peterman JS, Carper MM, Elkins RM, Comer JS, Pincus DB, Kendall PC. The effects of cognitive-behavioral therapy for youth anxiety on sleep problems. J Anxiety Disord. 2016;37:78-88.

55. Kahn-Greene ET, Lipizzi EL, Conrad AK, Kamimori GH, Killgore WDS. Sleep deprivation adversely affects interpersonal responses to frustration. Pers Indiv Differ. 2006;41(8):1433-1443.

56. Tzavela EC, Karakitsou C, Dreier M, et al. Processes discriminating adaptive and maladaptive internet use among European adolescents highly engaged online. J Adolesc. 2015;40:34-47.

57. Tzavela EC, Karakitsou C, Halapi E, Tsitsika AK. Adolescent digital profiles: a process-based typology of highly engaged internet users. Computers in Human Behavior. 2017;69:246-255.

58. Mai LM, Freudenthaler R, Schneider FM, Vorderer P. I know you've seen it! Individual and social factors for users' chatting behavior on Facebook Computers in Human Behavior. 2015;49:296-302. 